\title{
LUCUMON E MANSA WALY': DOIS HOMENS UM DESTINO
}

Ibrahima Diouf ${ }^{2}$

\begin{abstract}
Resumo
Lucumon deixou Tarquínia por Roma a fim de aceder ao poder real exatamente no início do exílio de Mansa Waly Gabu, também entre os sererês, onde o esperava um trono. Lucumon foi o primeiro rei de origem estrangeira a reinar em Roma, onde instalou a dinastia etrusca no poder, assim como Mansa Waly, também primeiro soberano estrangeiro, introduziu a realeza entre os sererês, onde reinou a dinastia dos Gelwaar.

Tanto um como outro, pode se impor, cada um em seu meio, graças a uma estratégia sabiamente calculada. Além das boas relações com as populações locais, cada um dos dois reis havia conseguido organizar casamentos entre suas famílias e os autóctones, a fim de reforçar seu poder.
\end{abstract}

\section{Palavras-chave}

Lucumon; Waly; exílio; Roma; sererê; rei; poder; origem; tradição; casamento.

\section{Résumé}

Lucumon avait quitté Tarquinies pour Rome afin d'accéder au pouvoir royal tout comme l'exil de Mansa Waly avait commencé au Gabou jusqu'en milieu sérère où l'attendait un trône. Lucumon fut le premier roi d'origine étrangère à régner à Rome où il installa la dynastie étrusque au pouvoir de même que Mansa Waly, premier souverain étranger, avait introduit la royauté en milieu sérère où régna la dynastie des Gelwaar.

\footnotetext{
${ }^{1}$ Lucumon foi o primeiro rei romano de origem etrusca. Depois de ter se instalado em Roma, adotou o nome de Tarquínio, como recordação de sua cidade natal, Tarquínia. Em língua etrusca, Lucumon significa rei, chefe supremo. Quanto a Mansa Waly, ele foi também o primeiro rei de origem estrangeira que reinou entre os sererês. O título Mansa significa rei em mandinga, uma das línguas nacionais codificadas no Senegal. Ele se chama Waly Mané.

2 Professor Doutor - Universidade Cheikh Anta Diop, Dakar, Senegal. E-mail: idiouf414@ gmail.com
} 
L'un comme l'autre ont pu s'imposer, chacun dans son milieu, grâce à une stratégie savamment calculée. En plus des bonnes relations avec les populations locales, chacun des deux rois avait réussi à organiser des mariages entre sa famille et les autochtones afin de renforcer son pouvoir.

\section{Mots clés}

Lucumon; Waly; exil; Rome; sérère; roi; pouvoir; origine; tradition; mariage.

\section{Introdução}

A cronologia do período real romano suscitou muitos debates entre os especialistas, sobretudo quanto à chegada e à duração do reino dos reis etruscos ${ }^{3}$. Mas depois da comparação de diferentes versões das narrativas referentes a esses acontecimentos, parece que um amplo consenso tenha sido encontrado concedendo mais crédito aos dados fornecidos pela tradição analística.

Da mesma forma, o início da realeza entre os sererês ${ }^{4}$ também suscitou controvérsias entre os detentores da tradição oral, principal fonte da história da África. Aliás, um relatório geral sobre as tradições orais especifica que "a África é o continente da oralidade. É pela tradição oral que podemos reconstituir a história da África profunda. Essa memória, na qual estão inscritos acontecimentos e comportamentos, é que garantiu a sobrevivência de nossas coletividades. Esse corpo vivo de conhecimentos tornou-se assim o elemento fundamental de nossa personalidade e de nossa unidade. A expressão oral é o instrumento que permitiu aos africanos, que então não tinham a escrita, acumular o saber e a experiência sob uma forma fácil de ser transmitida. A transmissão desse capital de sabedoria era de fato a condição necessária para a sobrevivência material e moral de nossos antepassados. ${ }^{\prime 5}$.

É por essa razão que em geral vamos nos basear nas tradições orais, além de algumas fontes escritas a fim de apresentar aspectos da história de Mansa

\footnotetext{
3 Tito Lívio, História romana; Dionísio de Halicarnasso, Antiguidades romanas; Martin 1998; De Cazanove 1988; Néraudau, 1979.

${ }^{4}$ Os Sererês são um grande grupo étnico presente principalmente no Senegal. Eles ocupam um espaço que corresponde mais ou menos às atuais regiões de Thiès, de Fatick, de Diourbel e de Kaolack. Os Sererês que vivem nas localidades próximas da cidade de Thiès, têm modos de falar que os distinguem dos outros cujos territórios correspondem à extensão do antigo reino sererê do Sine.

5 Preâmbulo do Relatório Geral do Colóquio internacional sobre as tradições orais do Gabou (Actes 1981: 7).
} 
Waly, um estrangeiro originário do $\mathrm{Gabu}^{6}$ e escolhido como rei entre os sererê. Todavia, tentaremos sempre que possível ter um olhar crítico para as narrativas dos vários autores, pois nos acontecimentos relatados as versões que embelezam e glorificam o passado dos grandes homens quase sempre predominam.

Para Lucumon também, os dados fornecidos pela tradição analística romana servirão de base para nosso trabalho, mas nem por isso seguiremos cegamente os relatos de autores antigos, nos quais se misturam muitas vezes história e lenda, mesmo se concedermos a estes, às vezes, a permissão de trazer algo do maravilhoso aos fatos puramente históricos.

É preciso determinar que o objeto deste trabalho não é o de reabrir o debate sobre a historicidade e as durações dos reinados dos reis etruscos em Roma, nem o de voltar a discussões em torno da odisseia e das realizações do soberano mandingue entre os sererês. Pensamos simplesmente em refletir sobre alguns aspectos da vida de Lucumon que vamos colocar em paralelo com episódios da vida de Mansa Waly a fim de mostrar que com a história podemos aproximar dois povos afastados no tempo e no espaço. Em outras palavras, o recurso da história pode permitir que se compreendam diferenças observadas em civilizações de épocas e/ou de meios diferentes, mesmo que saibamos que há realidades próprias a cada sociedade em sua evolução.

Por isso, que decidimos apresentar dois ilustres personagens com percursos idênticos em vários aspectos como suas origens, os motivos de seus exílios, as peripécias de suas viagens. Sua instalação numa nova pátria, a ascensão ao trono e a consolidação do poder real.

\section{As origens}

Lucumon tem uma origem grega longínqua. Segundo a tradição analística, seu pai Demarata deixara Corinto, uma cidade grega, durante a revolução de Cipselos contra a aristocracia dos Baquíadas ${ }^{7}$. Esse eupátrida corinto havia se refugiado em Tarquínia, uma cidade com a qual esse rico especialista em importação e exportação mantinha relações comerciais antes da revolução

\footnotetext{
${ }^{6}$ O Gabu era uma província que havia abrigado dignitários e príncipes vindos do império do Mali. Ele se estendia por uma parte da atual Guiné-Bissau, uma parte da Casamansa e uma parte de Gâmbia. Seu nome significa "País das águas" em mandinka.

7 Cazanove 1988: 636; Martin 1998: 22; Tito Lívio, História Romana, I, 34, 1 (aparato filológico por Jean Bayet e tradução por G. Baillet); Dionísio de Halicarnasso, Antiguidades romanas, III, 14,2 (aparato filológico e tradução por U. Fromentin).
} 
anti-oligárquica conduzida pelo tirano Cípselos ${ }^{8}$. Depois de ter se instalado na cidade que o acolheu Demarata desposou uma etrusca e teve com ela dois filhos Lucumon e Arruns. Este último morreu jovem, antes de seu pai, quando sua mulher estava grávida. E como Demerata ignorava a gravidez de sua nora, ele não pensou em seu futuro neto quando escreveu seu testamento. Depois de sua morte, apenas Lucumon foi o herdeiro de toda a fortuna de seu pai. Assim sendo, ficou rico e, por sua vez, também se casou com uma etrusca chamada Tanaquil ${ }^{9}$. Mas, apesar dessa fortuna, o casal não ficou bem em Tarquínia.

Essa versão é quase a mesma tanto entre os autores antigos quanto nos trabalhos mais recentes, por conseguinte, ela se aproxima da realidade histórica.

Quanto a Mansa Waly, se quisermos remontar às suas origens longínquas chegaremos até o império do Mali. Pertencendo a uma nobreza da época, chamada "Gelwaar"10, Mansa Waly tem antepassados que deixaram o Mali na época de Sundiata Keita, por volta dos anos 1250-1260. Esse período coincide com a expansão mandinga, da qual uma primeira etapa era o Gabu ${ }^{11}$, Província onde nasceu Mansa Waly, numa família principesca. Ele se casou com uma prima, de nome Selbé, uma princesa cuja traição seria a origem do exílio ${ }^{12}$ de seu marido que, afastado da sucessão do trono, começou a se sentir marginalizado.

Esse relato é quase invariável tanto na tradição do Gabu quanto entre os especialistas em história do mundo sererê. Essa convergência sobre a origem de Mansa Waly vista de fontes diferentes dá certa credibilidade à narrativa.

Vemos então que nos dois casos os dois homens viviam, cada um por seu lado, uma situação de desdém, de marginalização e de frustrações. Assim, a cada um, não restava senão a única ideia de partir.

\section{As razões de se exilar}

Existem versões diferentes sobre as causas do exílio de Mansa Waly do Gabu.

\footnotetext{
8 Tito Lívio, I, 34, 1 e as que se seguem; Dionísio de Halicarnasso s, III, 46 eas que se seguem; Martin 1985: 6; Will: 362; Martin 1976: 55-64.

9 Tito Lívio, I, 34, 1; Dionísio de Halicarnasso, III, 15, 2; Heurgon 1961: 103-111.

${ }^{10} \mathrm{O}$ poder político no Gabu estava entre as mãos de uma oligarquia de três grandes famílias: os Nhanco, os Manê e os Sanê; Os primeiros tinham sangue real e podiam reinar, enquanto os outros, mesmo sendo nobres, não podiam aspirar à realeza. São então os Nhanco que são os Gelwaar. Sobre a origem dos Gelwaar, ver Cissoko 1981a e b.

11 Gravrand 1983: 242.

12 Id. op.cit.: 304.
} 
Mas, a mais difundida é o conflito político a respeito de uma sucessão ao trono. Segundo a tradição oral, a partida precipitada dos Gelwaar, conduzidos por Mansa Waly, tinha como motivo os infortúnios passados numa guerra civil. Os príncipes gelwaar tinham, considerado, pelos fatos e causas, Mansa Waly como legítimo herdeiro do trono. Quando ele foi vencido por seu irmão mais novo, este lhe sequestrou o poder e expulsou seus partidários. Vejam esta versão extraída da tradição e relatada por Pinet-Laprade:

"Numa época distante de nós ao menos quatro séculos, Soliman-Koli reinava sobre o Gabu, país mandinka banhado pelo alto-Casamança. Quando de sua morte, seu irmão e sucessor natural ao trono, pretendeu herdar também seus bens e seus cativos; mas estes últimos não reconheceram seus direitos e se voltaram a Burê, filho de Soliman-Koli; a guerra sobreveio, Burê foi vencido e seus partidários se refugiaram no litoral. Alguns se estabeleceram nos mangues do baixo-Casamança, onde são conhecidos hoje com o nome de Diola; os outros atravessaram o país de Fogny, a Gâmbia, o país de Rip e o Salum, e fundaram seu primeiro estabelecimento em Mbissel, perto de Joal"13.

Esse relato contém lendas quando ele fala dos Diola como se fossem descendentes de uma parte dos refugiados saídos do Gabu, companheiros de Burê. Essa tese não resiste à prova dos fatos. Basta ler outros trabalhos o povoamento de Senegâmbia para se convencer disso ${ }^{14}$. A fundação de Mbissel também é anterior à chegada de Mansa Waly e sua delegação. Sobre essa questão, a tradição oral sererê é categórica. O que é mais interessante nesse relato feito por Pinet-Laprade é a fuga do Gabu, que é causada por um conflito na sequência de um problema de sucessão.

A outra versão fala de uma hostilidade, acompanhada de práticas de magia destinadas a eliminar a família dos Gelwaar. Essa explicação é dada por Félix Brigaud:

"Essa família era muito poderosa, e provavelmente ela causou inveja. Por isso teria ela sido enfeitiçada? Essa família era a dos Gelwaar. Todos os seus membros se foram desta vida, menos três: Beram Dikê, Sira Badiane e Wakumbof.

Esses três perceberam que havia algum problema no país de seus antepassados. Julgaram prudente sair de sua terra e encontrar um lugar menos nefasto para seus próximos. Montaram a cavalo e, seguidos pelos seus parentes que

13 Pinet-Laprade 1865: 131.

14 Sobre essa questão, ler os trabalhos de Cheikh Anta Diop: Diop 1979 (capítulo VII “Peuplement de l'Afrique à partir de la vallée du Nil”); Diop 1987 (capítulo X - “Migrations et formation des peuples actuels de l'Afrique") e o artigo de Yoro Dyâo (1913). 
haviam sido poupados pela morte, provavelmente porque conforme a algumas regras complicadas eles não podiam pretender ao poder. Junto com certo número de escravos e servidores, tomaram o rumo noroeste. Depois de vários dias a cavalgar, chegaram a Kulaar"15.

As "regras complicadas" de que fala o autor se referem ao matriarcado que estava em curso nas sociedades tradicionais africanas. Mas o que nos interessa aqui são as causas da ida para o exílio desse príncipe decaído, e que são, aliás, lembradas por um ilustre historiador senegalês, Yoro Dyao. Sua versão, narrada em seus cadernos publicados por H. Gaden, é a seguinte:

"Manyesa Ouali Dione era um Gelwaar do Gabu. Ao disputar o poder com Dang Sissé, foi vencido, perseguido, forçado a deixar o país, e seus aliados também foram expulsos uns após os outros. Assim se formaram sucessivamente os reinos de dinastias mandingas do sul de Senegâmbia: O Salum, o Kular, o Nyom e o Rip ${ }^{\prime \prime 16}$.

Essa explicação concorda com a de Pinet-Laprade, porém, Yoro Dyao se baseou numa tradição wolof ${ }^{17}$ na qual é citado o nome de Dang Sissé como vencedor de Mansa Waly. Em todos os casos, os motivos do exílio são invariáveis. O príncipe deixou sua pátria depois de uma derrota seguida de abusos. Todas essas versões são complementares ao sabermos que na África a guerra se faz, além do campo de batalha, também no plano místico. Temos então ter três explicações referentes às causas do exílio de Mansa Waly. Basta definir que o filho do rei só podia pretender aceder ao poder se sua mãe fosse da linhagem Nhanco, conforme às regras de sucessão baseadas no matriarcado em vigor nas sociedades negro-africanas na época. Pode-se então pensar que o conflito tinha oposto Burê (ou Burama) não ao irmão do falecido mas antes a seu próprio meio-irmão, como foi o caso em várias disputas intestinas em momentos de sucessão na África.

No que envolve os motivos de Lucumon ter saído de Tarquínia é que ele sofria com sua condição de filho exilado, porque os etruscos tinham certo desdém por aquele filho de um refugiado grego que lá se havia radicado. Mesmo sua mulher, Tanaquil, que pertencia à nobreza, foi destituída de sua alta posição social ${ }^{18}$. O casal sofria por causa de uma situação política medíocre devida à condição de mestiço de Lucumon, filho de um grego e de uma etrusca, o que

\footnotetext{
15 Brigaud 1962: 272-273.

16 Gaden 1912 (tiré à part, 31 p): 16.

17 Os Wolofs são um grupo sociolinguístico que vive no Senegal. Eles constituem a etnia majoritária cuja língua é falada por $90 \%$ dos Senegaleses.

18 Tito Lívio, I, 34, 1.
} 
sua esposa não podia suportar. Assim, ela levou o marido a deixar Tarquínia para buscar um destino mais brilhante ${ }^{19}$. A situação do casal em Tarquínia era uma vergonha insuportável para Tanaquil. Assim, desprezando o instinto que os ligava à pátria, a mulher convenceu Tarquínio a deixar sua cidade natal para ir a Roma, onde parecia poder resolver a questão. Seus propósitos são relatados por Tito Lívio nestes termos:

“Entre esse povo novo, onde logo se conseguia a nobreza e apenas por mérito, deveria haver lugar para um homem corajoso e empreendedor. Um dos reis anteriores, Tatius, era Sabino; foram procurar Numa, em Cures, para fazê-lo rei; Ancus tinha uma Sabina por mãe e como retratos de seus antepassados apenas o de Numa"20.

Tanaquil deve ter ouvido indícios da situação sociopolítica e econômica que predominava naquela cidade. Pelo final do século VII, Roma era incontestavelmente um dos maiores polos de atração para um "cavaleiro de aventuras". A cidade se apresentava com estruturas sociopolíticas "abertas", com um início de sua "decolagem" econômica; ela passou por 'sua primeira verdadeira expansão territorial às expensas do Lácio, sob o impulso do rei Ancus Marcius, neto de Numa" 21 . Todos esses fatores, que eram vantagens que poderiam facilitar uma incursão na política, habilmente destacados por Tanaquil, encorajaram seu marido a se lançar numa aventura para "buscar fortuna" e uma melhor posição social naquele meio onde ele poderia ser mais facilmente respeitado do que em Tarquínia.

Aqui também é possível notar que os dois personagens, Lucumon e Mansa Waly, eram mais motivados pela busca do poder do que por um simples gosto pela aventura. Ambos devem ter tido informações claras sobre o lugar de suas destinações e sobre as oportunidades que poderiam lhes oferecer. Deve-se também citar o papel do saber místico. Quando uma águia pegou o chapéu de Lucumon e o levou em voo até a altura do monte Janículo para em seguida recolocá-lo em sua cabeça, Tanaquil concluiu que aquele prodígio anunciava o poder 22 . A "Sombra" mística (Ginaaru) que guiava Mansa Waly também lhe anunciara um trono a ser ocupado ${ }^{23}$. A esperança de encontrar um lugar melhor deve tê-los encorajado a empreender as viagens com seus riscos e perigos.

\footnotetext{
${ }^{19}$ Martin, 1985: 6.

20 Tito Lívio, I, 34, 1-2; Dionísio de Halicarnasso III, 15, 3.

${ }^{21}$ Martin 1976: 153 e 258.

22 Tito Lívio, I, 34.

${ }^{23}$ Gravrand, 1983: 275.
} 


\section{As odisseias de Lucumon e de Mansa Waly}

Segundo a versão mais difundida da tradição analítica, Lucumon deixou sua terra, Tarquínia, para ir diretamente a Roma onde adotou o nome de Tarquínio para lembrar de sua cidade natal. Ele era um hóspede pacífico, notável por sua riqueza, sua generosidade e seu senso das relações humanas. Mas essa apresentação da viagem de Lucumon e sua esposa Tanaquil parece muito simplista. É bem possível que Lucumon tenha chegado a Roma á frente de um grupo de aventureiros e de empregados visto sua riqueza e o status social de sua esposa. Essa hipótese é justificada pelo fato de que o casal, antes de deixar sua cidade de origem, tinha amadurecido um plano de chegar ao poder em Roma. Q qualquer que fosse a situação de abertura e, talvez, de degradação política em Roma, o casal não poderia ter decidido se instalar numa cidade tão belicosa e famosa por suas veleidades expansionistas sem ter previamente tomado as disposições necessárias para o sucesso do empreendimento. Aliás, esse é todo o sentido dos propósitos de Tanaquil citados anteriormente. Podemos imaginar então essa chegada do casal a Roma de outra forma. Já vimos que o Lácio se apresentava como um tipo de "Novo Mundo" por volta do século VII, e essa época correspondia ao poder da Etrúria, cada vez mais dinâmica e empreendedora. Era, aliás, a época na qual a cidade havia iniciado sua expansão (uma colonização dos tempos modernos) da Itália central até a Campânia, mas também para o norte e até a Córsega ${ }^{24}$. Nessas circunstâncias, a chegada de Tarquínio ao poder parece mais uma etapa dessa expansão etrusca ${ }^{25}$. E ainda que Tanaquil continue sendo o elemento motor, essa iniciativa contou com a ajuda de sua cidade natal, como também a da cidade de Veios, provavelmente ${ }^{26}$. Essa possibilidade é mais que imaginável ao sabermos que a Etrúria influenciou grandemente as práticas adivinhatórias em Roma, e que Veios sempre foi a inimiga jurada dos Romanos ${ }^{27}$.

Logo, quando se fala, nesse relato, de um casal vindo num carpentum (carroça de duas rodas, coberta) pela colina do Janículo, pode-se pensar nesse aventureiro ainda na margem etrusca do Tibre de onde tinha uma vista panorâmica de Roma.

A viagem de Lucumon foi pouco movimentada ao que parece, contrariamente à odisseia de Mansa Waly desde o Gabu até à terra dos sererês. Segundo

\footnotetext{
${ }^{24}$ Heurgon 1961: 107.

${ }^{25}$ Heurgon 1985: 261 e 265.

${ }^{26}$ Alföldi 1965: 207; Heurgon 1985: 242; Richard 1978: 312.

27 Tito Lívio, I, 42; II, 6;
} 
uma versão tradicional, recolhida por Fata Ndiaye ${ }^{28}$, a partida do Gabu aconteceu no sétimo dia do mês lunar quando uma "sombra misteriosa apareceu ao chefe" e permitiu a Mansa Waly e seu séquito deixar sua pátria para iniciar um périplo rico em consequências.

Depois da derrota, era preciso agir rápido, pois nas horas que se seguem a um fracasso militar as medidas tomadas pelo vencedor são quase sempre excessivas. Assim, os fugitivos (príncipes, princesas, guerreiros, servidores fiéis e outros subordinados) estavam sujeitos aos mesmos castigos em caso de captura. Os príncipes em desgraça reunirão apressadamente seus próximos, dos quais a tradição oral conservou alguns nomes: Burama, Badiar Manê, Mady Badiar Manê, Sira Badiar Manê e Takura Badiar Senghor. À frente desse grupo, estava Waly Manê, que depois se tornaria Mansa (rei) do Sine ${ }^{29}$.

Teriam os fugitivos algum plano bem urdido antes de deixar o Gabu? Nenhuma informação nos permite até hoje responder a essa pergunta. Sua primeira intenção era primeiramente se colocar em segurança, enquanto esperava eventuais negociações e uma provável reconciliação. Mas um projeto para criarem uma entidade sociopolítica na fronteira do Gabu não pode ser afastada, visto a geopolítica da África Ocidental na época. Alguns recortes de datas aproximativas fornecidas pelos autore ${ }^{30}$ que recolheram tradições orais permitiram situar a odisseia dos Gelwaar por volta de 1324 ou 1330. Esse período corresponde à expansão Mandinga para a África Ocidental: KanKan Mussa volta da peregrinação a Meca, Sunkaré Manê impôs seu domínio ao Tekrur (Futa); no Gabu, o espaço Mandinga se ampliou ${ }^{31}$.

Foi nesse contexto que Mansa Waly e seu séquito atravessaram riachos, permaneceram nas florestas lutando contra vários perigos (animais selvagens, serpentes venenosas, vegetação com venenos mortais, espíritos malignos, etc.). Seguindo as indicações daquela "sombra" mística, Mansa Waly continuou sua viagem movimentada em direção a uma terra desconhecida. Desde o revés do Gabu, príncipes e princesas se encorajavam mutuamente diante

${ }^{28}$ Fata Ndiaye, ex-diretor de escola, fez uma comunicação inédita nas primeitas jornadas culturais do Sine, intitulada: "La saga du peuple sérère et l'histoire du Sine", p. 40. Essas jornadas aconteceram em Fatick e em Diakhao, última capital do reino do Sine, de 10 a 13 de maio de 1991 (Ndiaye 1992).

29 Diouf 1972: 703-705.

30 Pinet-Laprade, 1865: 131; Aujas 1931: 294-296; Bourgeau 1933: 2-6; Gaden 1912: 16; A. Sarr 1948: 832-837; P. Diagne 1965: 142-148.

${ }^{31}$ Cornevin; Cornevin 1964: 162-165; Lugan 2009: 233. Ver principalmente a nota 1 onde o autor explica a expansão mandinga em várias direções. "Des groupes partirent vers l'ouest, vers le fleuve Gambie ou en direction du pays des Sérères". 
das numerosas dificuldades e da série de desgraças, como relata H. Gravrand com estas palavras:

\footnotetext{
"Aqui um servo desaparecia, perdido na floresta profunda ou morto por alguma fera, ali um guerreiro era picado por uma cobra e morria em pouco tempo. Num outro dia, a Sombra não aparecia nos bosques de troncos esguios e a vanguarda ficava andando em círculos, fazendo a caravana se perder" 32 .
}

Apesar de todas essas dificuldades, a Sombra guiou Mansa Waly e seu séquito até Kulaar ${ }^{33}$, primeiro reino gelwaar no Salum, depois, de escala em escala, a delegação acabou por se instalar definitivamente em Mbissel, no Sinê. Visto as múltiplas e diversas peripécias observadas durante a odisseia de Mansa Waly, tudo parece mostrar que sua partida foi tão precipitada que ele não teve tempo para estabelecer um plano de viagem. Foi exatamente o contrário de Lucumon, que amadurecera bem seu projeto antes de deixar sua cidade natal. Entretanto, cada um pode chegar a sua destinação e mesmo conseguir chegar às mais altas funções políticas no meio em que foi recebido.

\section{Acesso ao poder}

Ao contrário de Roma, onde a realeza existia desde o século VIII A. C., entre os sererês não havia poder central, com um único indivíduo à frente. Havia patriarcas que faziam a justiça e administravam os homens, cada um em sua zona: esses chamados Iaman ${ }^{34}$ às vezes se reuniam para resolver questões importantes no tocante à comunidade, porque a sociedade sererê era igualitária em todos os setores. Nessa época, (século XIV) o país sererê estava dividido em sete costados, cada um com seu Iaman à frente:

- laman ou jaraaf de Palmarin chamado lam songo ou jarno juala, residente em Palmarin;

- laman ou jaraaf de Fadial chamado Diamé Ngom, residente em Fadial;

- laman ou jaraaf de Njaafaaj appelé lam njaafaaj, résidant à Nqayooxeem;

- laman ou jaraaf de Ndoq chamado Waal saatiim o Ndoq, residente em Ndoq;

${ }^{32}$ Gravrand 1983: 261.

${ }^{33}$ Kulaar é a primeira província sererê do Salum (atual região de Kaolack) onde se instalaram os Gelwaar depois de sua saída do Gabu. Foi em Kulaar que Mansa Waly teria deixado sua irmã se ocupar da administração da província antes de continuar para Dionick, Moudé, Sangomar, Fadiouth, Fadial e Mbissel (Diouf 1972: 704-706; Gravrand 1983: 276-288).

${ }^{34} \mathrm{O}$ laman era um grande proprietário de terras, de quem se podia herdar superfícies a serem cultivadas. 
- laman ou jaraaf de Gagnègue chamado lam Gagnègue, residente em Gagnègue;

- laman ou jaraaf de Ndimague chamado Jokel Jarno, residente em Ndomague;

- laman ou jaraaf du Baol chamado Demba Gueye, residente em Lambay ${ }^{35}$.

Foi nesse contexto sociopolítico que Mansa Waly chegou em Fadial, onde ele foi recebido, ele e seu séquito, por Diamé Ngom, que o instalou em seguida em Mbissel, numa tarde de domingo ${ }^{36}$. Essa instalação dos Gelwaar foi tão pacífica depois de algum tempo, os hóspedes se tornaram bons vizinhos das populações sererês da aldeia e seus arredores. Mansa Waly não demorou a manifestar sua sabedoria mostrando-se um bom estrategista e perito em justiça social quando uma boa oportunidade se apresentou a ele. Uma contestação num caso de sucessão havia oposto dois camponeses que brigavam por um rebanho de bois. Havia cinco ou sete anos ${ }^{37}$ que a justiça "lamanal" não conseguia julgar o caso. Um Sererê do Baol havia confiado seu rebanho de bois a um boiadeiro de Fadial antes de voltar a sua aldeia, Lambaye onde morreu logo depois. Seu sobrinho, Wa Ngom (wa é o diminutivo de Waly), veio reclamar o rebanho mas a cada vez sua queixa era rejeitada pelo tribunal dos laman, por falta de provas. Finalmente o caso foi enviado a Mansa Waly que, para a sessão dos Iaman no início da invernagem, convocou os dois queixosos, cada um com sua esposa e seu filho mais novo. Ele colocou cada criança numa cavidade de uma manjedoura e pediu a cada pai que ficasse com ele em equilíbrio sobre a cabeça durante um certo tempo. Depois pediu que as mães fizessem o mesmo. Sabe-se que ao menor movimento da cabeça, o enorme tronco cavado podia cair, ferindo ou até mesmo matando a criança. Com esse teste repetido, num equilíbrio tão frágil, o juiz esperava que alguém, não aguentando, revelasse a verdade. E, de fato, a mulher do boiadeiro acabou por pedir a seu marido que devolvesse o rebanho a seu proprietário, pois aquilo não valia a perda de um filho. A população de Mbissel e os Iaman presentes propuseram então que Mansa Waly se tornasse seu chefe. Ele se torna assim o primeiro rei, no verdadeiro sentido da palavra, no meio sererể ${ }^{38}$.

${ }^{35}$ O Jaraaf era um grande dignitário, equivalente ao que se chama hoje, chefe de aldeia. À frente de cada uma das localidades sereres (Palmarin, Fadial, Njaafaaj (Nqayooxeem), Ndoq, Baol (Lambay), havia um laman, un dignatário. Para mais detalhes vrr Gravrand 1983: 238 e 293; Diouf 1972: 42.

36 Ndiaye 1992: 41.

${ }^{37}$ Na Chronique de Niokhobaye, o litígio durava havia cinco anos, enquanto no Cosaan de H. Gravrand, o sobrinho do morto pleiteava havia sete ans. As outras versões da tradition oral nnão dão a duração.

38 Gravrand 1983: 294-295; Diouf 1972: 705. Para ele, Mansa Waly aceitara a proposta mas desde que tivesse Wa Ngom a seu lado. Deve-se observar que se tratava mais de ter os laman presentes, entre os quais Diamé Ngom de Fadial, a seu lado como conselheiros. 
E por não conseguirem pronunciar "Mansa», os sererês o chamaram de Maïssa Waly Mané.

Aqui, a ascensão de Waly Mané ao trono recentemente instalado se fez através de um plebiscito das populações de Mbissel e dos Iaman vindos de outras partes do país sererê, assim como em Roma, a chegada de Lucumon ao poder real acontecera graças a uma estratégia sabiamente organizada para seduzir a população romana. Lucumon, certamente, não chegou como um conquistador nem com um exército, mas tampouco como um refugiado, nem como simples “operário imigrante». Segundo P.M. Martin,

"não se deve ver essa chegada do casal a Roma dentro de um tosco grupo de 'operários imigrantes', mas antes, como diz uma corrente tradicional, como chefe guerreiro de um grupo de "fregueses" - ou de sua gente e vassalos. Sua influência, suas qualidades militares, seus homens, suas riquezas, Tarquínio, de comum acordo com sua mulher, colocou a serviço do rei Ancus, então às voltas com vizinhos de Roma". ${ }^{39}$

Com esses gestos, Tarquínio acabou por ser o braço direito do rei que the confiou até mesmo a educação de seus filhos. Essa proximidade com Ancus e a generosidade com o povo fizeram de Tarquínio um homem influente e amado pelos Romanos. Por isso, depois da morte de Ancus, Tarquínio insistiu para que se reunissem os comitês que deveriam escolher o novo rei. Uma vez fixada a data, o candidato etrusco usou como pretexto uma caçada para afastar os filhos de Ancus $^{40}$ e afastá-los da eleição ${ }^{41}$. Os filhos de Ancus Marcus nunca digeriram a sucessão de seu falecido pai por aquele homem de origem estrangeira. Mas essa versão é discutível, pois se sabe que a realeza romana não era hereditária e os filhos do rei morto ainda não tinham atingido a idade adulta. Melhor ainda, Tarquínio havia ganhado a confiança dos romanos e também lançado sua campanha bem cedo. Foram certamente essas razões que lhe permitiram ser plebiscitado no momento da eleição. Tanto em Roma quanto entre os sererês, o acesso ao poder real aconteceu de maneira pacífica. Lucumon conseguira ser Romano entre os Romanos, assim como Mansa Wali havia se integrado perfeitamente na vida dos Sererês. As relações de amizade e de fraternidade tecidas com as populações locais facilitaram o exercício do poder.

\footnotetext{
${ }^{39}$ Martin 1985: 7.

40 Tito Lívio, I, 4, 35.

${ }^{41}$ Tito Lívio, I, 35, 1.
} 


\section{Consolidação do poder real}

Logo que Tarquínio, o velho, assumiu o poder real em Roma, ele reforçou as relações de amizade com o povo, principalmente com os Patrícios ${ }^{42}$. Essa relação de confiança entre o novo rei e a aristocracia romana constituía uma certa garantia de estabilidade, pois na época Roma se defrontava ainda com perturbações internas e ameaças externas. As cidades conquistadas por Marcus (Fidenas, Veios, Politoria, Gabias...) ainda ameaçavam se rebelar contra Roma ${ }^{43}$. Era preciso, portanto, neutralizar os inimigos desde o interior ${ }^{44}$ e subjugar as cidades rebeldes da vizinhança ${ }^{45}$. Tarquínio, o velho tentou primeiro se reconciliar com os filhos de Ancus Marcus, que não paravam de lhe colocar obstáculos, acusando-o de assassinato, como o de Atius Nevius, e tentando sublevar o povo contra ele ${ }^{46}$. Tarquínio também fez sua filha se casar com seu filho adotivo Servius Tullius ${ }^{47}$, para reforçar os laços matrimoniais com as populações autóctones, os Romanos, fazer esquecer suas origens estrangeiras e consolidar seu poder. Apesar de todas as suas precauções, Tarquínio, o velho acabou por ser assassinado ${ }^{48}$. Entretanto, sua estratégia baseada nas relações matrimoniais havia permitido que os reis de origem etrusca conservassem o poder real.

Des liens matrimoniaux avaient également permis à Mansa Waly Mané d'instaurer en milieu sérère une royauté héréditaire dont la succession passait par la lignée maternelle de l'héritier. Foram laços matrimoniais também que permitiram a Mansa Waly Manê instaurar entre os sererês uma realeza hereditária, cuja sucessão passava pela linhagem materna do herdeiro. Finalmente, estratégico que era, Maïssa ${ }^{49}$ (Mansa Waly) pedira primeiro a colaboração dos laman presentes no momento da sessão realizada com Diamé Ngom, em Fadial. Ao propor fazer de Maissa Waly seu maad-nqel ${ }^{50}$,

42 Tito Lívio, I, 34, 11; Dionísio de Halicarnasso, III, 15, 5.

${ }^{43}$ Dionísio de Halicarnasso, III, 13, 1-4 e III, 13, 7-13; Tito Lívio, I, 36 e I, 38.

${ }^{44}$ Dionísio de Halicarnasso, III, 21, 3-8 e III, 22, 1-4.

${ }^{45}$ Dionísio de Halicarnasso, III, 16, 1-13; III, 17, 1-4; III, 18, 1-9.

46 Dionísio de Halicarnasso, III, 22, 1-6 e III, 21, 7; Tito Lívio, I, 36, 1-3. Atius Navius era um famoso adivinho que se opôs ao aumento das centúrias de cavalaria por Tarquínio sem consultar aos adivinhos. As únicass criadas por Romulo eram as dos Ramnes, dos Tities e dos Luceres com o acordo dos adivinhos.

47 Tito Lívio, I, 39, 1 e as que se seguem; Dionísio de Halicarnasso, IV , 1, 2.

48 Tito Lívio, I, 40; Dionísio de Halicarnasso, III, 22, 7.

49 Nós utilizamos agora o nome de Maïssa em lugar de Mansa pois a partir de sua subida ao poder era o primeiro nome que passa a ser conhecido e utilizado.

${ }^{50}$ Maad significa estar presente, presidir; maad-nqel significa aquele que préside as reuniões em praça pública, em, outras palavras, o rei. 
esses laman e a população não pensaram que acabavam de oferecer um trono a um príncipe derrotado em busca de uma coroa. Depois de ter destronado os Iaman, para ficar seguro de ter um poder estável e duradouro, Maissa (Mansa) Waly suplantou da mesma forma os saltigi (adivinhos), pois suas profecias eram sempre realizadas. Ele ampliou assim o seu prestígio, já que na época o valor de um homem era função da infalibilidade de suas predições, e nessa área a sombra mística ${ }^{51}$ que o acompanhava era de uma eficácia inigualável entre os sererês. Na época, depois das colheitas, eram organizadas sessões de luta tradicional. Mbissel sendo a capital da província, local de residência do novo rei, naquele ano houve um grande campeonato de luta. Os participantes vinham de todas as partes do país sererê, entre as quais uma aldeia chamada Djilakh onde morava, Bougar Biram Faye, um lutador de grande talento em seu grupo, Desde o começo, Téning Diom, a sobrinha do rei Maïssa Waly notara aquele rapaz. Ela acabou por se confiar a seu tio que não esperava mais que essa bela ocasião para atar suas sólidas alianças com as famílias sererês mais ilustres. Esse casamento sabiamente calculado permitiu que Maissa Waly instaurasse firmemente um sistema político cuja descendência uterina seria a maior beneficiária ${ }^{52}$. Nesse sistema, a nobreza era transmitida pela mãe, assim, só poderia ser rei do Sine um homem cuja mãe fosse Kelwaar (singular de Gelwaar). Foi assim que com a morte de Maissa Waly, foi um filho de Téning Diom, Tassé Faye, que o sucedeu.

E contrariamente a Tarquínio, que foi morto, Maissa Waly morreu depois de uma longa enfermidade, o que lhe valeu o apelido de "Jon"53 (Dione). Mas os dois têm em comum essa capacidade de adaptação ao meio que o acolhe e a inteligência de tecer relações matrimoniais com os autóctones a fim de apagar qualquer sentimento de frustração ao verem estrangeiros usurpar um poder real.

${ }^{51}$ Essa Sombra que guiava os Gelwaar se chamava Ginaaru, e era um espirito protetor (fangool en sérère). Ver Diouf 1972: 704; Gravrand 1983: 261.

52 Gravrand 1983: 301; Diouf 1972: 705. O sistema matriarcal era o que vigorava no reino do Sine. Ainda que o rei fosse um Kelwaar (singulier de Gelwaar) seu filho só podia pretender ao poder se sua mãe fosse Kelwaar.

53 Jon (termo serere) significa "desperto", "vivo". Durante a longa enfermidade de Maïssa Waly, as populações pediam frequentement ntícias do rei e lhes respondiam: "oxaa Jon". "Ele está desperto", isto é, ele está vivo. A posteridade continuará a acrescentar essa palavra "Jon" ao nome de Maïssa Waly, já que ele corresponde foneticamente a um nome serere: Dione. Por isso se diz hoje Maïssa Waly Dione, sobretudo entre os cantores. 


\section{Conclusão}

Essas reflexões sobre Lucumon (Tarquínio, o Velho) e Mansa Waly (Maissa) mostram que os dois personagens históricos compartilham vários pontos de convergência em suas vidas, mas existem também aspectos divergentes em seu passado. Ambos deixaram a pátria de origem depois de ter sofrido uma derrota, tendo sentido o desprezo do vencedor, em suma, cada um deles sentiu que estaria em dificuldades ali onde esperava ocupar o topo da pirâmide social. Ambos foram condenados a abandonar a terra natal quando esperavam ocupar as mais altas funções da entidade sociopolítica e desfrutar de uma maior consideração.

Lucumon foi vítima se seu status de estrangeiro, sendo filho de Demarate, um exilado grego estabelecido em Tarquínia. O desdém dos etruscos por Lucumon causava vergonha, sobretudo para sua mulher, Tanaquil, que descera de sua alta classe social por ter se casado com esse filho de um refugiado. Essa situação constituiu o principal motivo da partida do casal para ir em busca de melhores paragens em Roma. Quanto a Mansa Waly, sua saída do Gabu para encontrar uma terra de adoção segura entre os sererês foi motivada por uma derrota num conflito de sucessão ao trono. $\mathrm{O}$ medo de represálias, a vergonha de ser um príncipe decaído e a esperança de encontrar um lugar favorável para seu projeto precipitaram as coisas.

Ambos os exilados foram movidos por altas ambições e esperanças baseadas em mensagens encorajadoras provinda de forças sobrenaturais. Certamente, a aventura de Lucumon teve menos peripécias que a odisseia de Mansa Waly, mas ao fim de cada uma das trajetórias havia um trono a ser ocupado por eles. Um foi o fundador da dinastia etrusca à qual pertenceram os três últimos reis romanos; o outro foi o primeiro da família Gelwaar a ocupar o trono do Sinê, uma dinastia que permaneceu no poder durante toda a duração da realeza. Os dois foram os primeiros reis de origem estrangeira a reinar em suas novas pátrias. Usaram de sua genialidade para ganhar a confiança do povo e fazer alianças matrimoniais sabiamente calculadas a fim de consolidar seu poder.

Apesar de todas essas convergências entre as vida de Lucumon e a de Mansa Waly, nada nos autoriza a falar de alguma ligação existente entre as duas sociedades. O que, antes disso, deve ser observado, é que o espírito humano sendo o mesmo em toda parte, é natural que possam ser notadas convergências entre civilizações tão afastadas umas das outras. Mostrar os aspectos idênticos seja na área política como sociocultural e religiosa ajuda a entender melhor as diferenças aparentes entre os povos e buscar uma relação cultural numa civilização universal. 


\section{Bibliografia}

\section{Trabalhos sobre Roma}

\section{Fontes}

Denys d'Halicarnasse. Antiquités romaines. Texte établit et traduit par U. Fromentin. Paris: Les Belles Lettres, 1998.

Tite-Live, Histoire romaine. Texte établi par Jean Bayet et traduit par G. Baillet. Paris: Les Belles Lettres, 1954.

\section{Obras gerais}

ALFÖLDI, A. Early Rome and the Latins. Michigan: The University of Michigan Press, 1965.

HEURGON, J. La vie quotidienne chez les Etrusques. Paris: Hachette, 1961. . Rome et la Méditerranée occidentale jusqu'aux guerres puniques. Paris: PUF, 1985.

MARTIN, P. M. Le souci chronologique dans la tradition sur la généalogie des Tarquins, dans Aiôn. Le temps chez les Romains. Paris: Payot, 1976.

NERAUDAU, J.-P. La jeunesse dans la littérature et les institutions de la Rome républicaine. Paris: Les Belles Lettres, 1979.

RICHARD, J. C. Les origines de la plèbe romaine: essai sur la formation du dualisme patricio-plébéien. Rome, 1878.

WILL, E. Korinthiaka. Recherches sur l'histoire et la civilisation de Corinthe des origines aux guerres médiques. Paris: Editions Boccard, 1955.

\section{Artigos}

DE CAZANOVE, O. La chronologie des Bacchiades et celle des rois étrusques de Rome. Mélanges de l'École française de Rome. Antiquité, tome 100, n², Rome, 1988 , p. 615-648.

MARTIN P. M. Tanaquil, la "faiseuse de rois". Latomus, T 44, Fasc., Bruxelles, Société d'Étude Latines, 1985, p. 5-15.

Temps historique, temps mythique dans le Livre I de Tite-Live. Vita Latina, $\mathrm{n}^{\circ} 149$, Paris, 1998, p. 17-33. 


\section{Trabalhos sobre os sererês}

\section{Obras gerais}

[ACTES du] Colloque international sur les traditions orales du Gabou (19-24 Mai 1980). Ethiopiques. Revue Negro-Africaine de Littérature et de Philosophie, n. 28 (numéro spécial). Dakar, 1981.

CORNEVIN R. et CORNEVIN, M. Histoire de l'Afrique, des origines à la $2^{\circ}$ Guerre Mondiale. Paris: Payot, 1964.

DIOP, C. A. Nations Nègres et culture. Paris: Présence Africaine, 1979. L'Afrique noire précoloniale. Paris: Présence Africaine, 1987.

GRAVRAND H., La civilisation sereer: Cosaan. Dakar: N.E.A., 1983.

LUGAN, B. Histoire de l'Afrique, des origines à nos jours. Paris: Ellipses Editions Marketing, 2009.

\section{Artigos}

AUJAS, L. Les Sérères du Sénégal. B.C.E.H.S.A.O.F., 3, 1931, p. 293-334.

BECKER, C. et MARTIN, V. Notes sur les traditions orales et les sources écrites concernant le royaume du Sine. Bulletin de l'Institut Fondamental d'Afrique Noire, série B, Tome XXXIV, n. 4, octobre 1972, p. 732-777.

BOURGEAU, J. Note sur la coutume des Sérères du Sine et du Saloum. B.C.E.H.S.A.O.F., 1, 1933, p. 1-65.

BRIGAUD F. Histoire traditionnelle du Sénégal. Etudes sénégalaises, n 9, fascicule 9, Saint-Louis du Sénégal, 1962, p. 146-278.

CISSOKHO, S. M. Introduction à l'histoire des Mandingues de l'Ouest, l'empire du Gaabu. De l'organisation politique du Gaabu. Actes du Colloque International sur les traditions orales du Gaabu. Ethiopiques, 28, Dakar, 1981, p. 73-91 et 195-206.

DIAGNE, P. Royaumes sérères. Présence Africaine, 54, Paris, 1965, p. 142-172.

DIOUF, N. Chronique du royaume du Sine. Bulletin de l'Institut Fondamental d'Afrique Noire, série B, tome XXXIV, n. 4, octobre 1972, p. 702-732.

DYAO, Y. Les six migrations venant d'Égypte auxquelles la Sénégambie doit son peuplement. In: DELAFOSSE, M. et GADEN, H. Chronique du Fouta sénégalais. Paris: Éditions Leroux, 1913, p. 123-131. 
GADEN H. Légendes et coutumes sénégalaises. Revue d'Ethnologie et de Sociologie, 1912, tiré à part, $31 \mathrm{p}$.

MANE, M. Contribution à l'histoire du Kaabu, des origines au XIX siècle. Bulletin de l'Institut Fondamental d'Afrique Noire, série B, tome 40, n. 1, Dakar, 1978.

NDIAYE, F. La saga du peuple sérère et l'histoire du Sine. Actes des Journées culturelles sérères de 1991 à Fatick et Diakhao. Ethiopiques. Dakar, 1992, pp. 38-44.

PINET-LAPRADE, E. Notice sur les Sérères. Annuaire du Sénégal et dépendances. 1865, pp. 129-171.

SARR, A. Histoire du Sine-Saloum. Présence Africaine, 5, Paris, 1948, pp. 832-837.

CISSOKO, S. M. Introduction à l'Histoire des Mandingues de l'Ouest, l'empire du Gabou». [Actes du] Colloque international sur les traditions orales du Gabou (19-24 Mai 1980). Ethiopiques. Revue Negro-Africaine de Littérature et de Philosophie, n. 28 (numéro spécial). Dakar, 1981a, p. 73-91.

De l'organisation politique du Gabou. Colloque international sur les traditions orales du Gabou. [Actes du] Colloque international sur les traditions orales du Gabou (19-24 Mai 1980). Ethiopiques. Revue Negro-Africaine de Littérature et de Philosophie, n. 28 (numéro spécial). Dakar, 1981b, p. 195-206. 